\title{
Pre- and postmarathon training habits of nonelite runners
}

This article was published in the following Dove Press journal:

Open Access Journal of Sports Medicine

3 March 2011

Number of times this article has been viewed

\section{Angela M Voight ${ }^{\prime}$ \\ William O Roberts' \\ Scott Lunos ${ }^{2}$ \\ Lisa S Chow ${ }^{3}$}

'Department of Family Medicine and Community Health; ${ }^{2}$ Biostatistical Design and Analysis Center, Clinical and Translational Science Institute; ${ }^{3}$ Department of Medicine, Division of Diabetes, Endocrinology and Metabolism, University of Minnesota, Minneapolis, MN, USA
Correspondence: Lisa Chow 420 Delaware St. SE, MMC I0I, Minneapolis, MN 55455, USA

Tel + I 6126258934

Fax+l 6126263133

Email chow0007@umn.edu
Background: Despite the increasing popularity of marathons, little research has examined the training habits of nonelite marathon runners. Given that nonelite runners, particularly those with a competitive motive, have a higher risk for injury than experienced elite runners, it is important for physicians to understand the training program and features that might distinguish running performance and injury rates in this population.

Hypothesis: We hypothesized that nonelite runners who qualify for the Boston Marathon ("qualifiers") would have higher running volumes, more running sessions per week, lower injury rates, and lower body mass index (BMI) than nonqualifying runners.

Study design: A cross-sectional Web-based survey of runners (convenience sample) at 1 month $(\mathrm{n}=50)$ and 6 months $(\mathrm{n}=41)$ after participation in the 2008 Twin Cities Marathon (TCM) that acquired data on anthropometric measures, demographic data, finishing time, premarathon/ current training program, and self-reported injury.

Results: Thirteen of 50 initial survey respondents were classified as a "qualifier" based on their finishing time. Mean BMI was significantly lower in the qualifiers at 1 month ( 22.0 versus $23.9 \mathrm{~kg} / \mathrm{m}^{2}, P=0.0267$ ) but not 6 months postmarathon. There were no significant differences in training volume (running frequency, run length, or cross-training volume) or injury rates between qualifiers and nonqualifiers. Prior to the 2008 TCM, 54\% of runners included crosstraining in their exercise program, which increased significantly to $74 \% 1$ month postmarathon $(P=0.0039)$ and $71 \% 6$ months postmarathon $(P=0.0325)$. There was no association between cross-training and injury rates.

Conclusions: Nonelite marathon runners had a high degree of cross-training in their training program. Qualifiers for the Boston Marathon did not significantly differ in running frequency, run length, or cross-training volume compared with nonqualifiers. Whether changes in the training program at an individual level might facilitate a change in qualifying status remains to be determined.

Keywords: training, marathon, cross-training, BMI

\section{Introduction}

Marathon running is increasing in popularity. In 1980, there were approximately 143,000 US marathon finishers. By 2009, the number had risen to 467,000 US marathon finishers. ${ }^{1}$ The median finishing times and ages for marathon finishers have also increased since 1980, indicating an increase in nonelite runners. ${ }^{1}$ Little has been published about the running habits of nonelite marathon finishers, particularly with regard to their anthropomorphic measures and pre-and postmarathon training programs. This information is critical, as running-related injury associated with marathon training can 
be observed in up to $90 \%$ of runners, ${ }^{2}$ with fewer experienced runners having high rates of injury than nonexperienced runners. ${ }^{2,3}$

Running performance has been associated with anthropomorphic measures such as body mass index (BMI), percentage of body fat, skin fold measurements, and extremity girth $^{4-6}$ and with training variables such as volume, intensity, and type. ${ }^{7}$ The relative importance of anthropomorphic factors versus training volume in endurance athletes remains controversial. ${ }^{8-11}$ A combination of training factors and low $\mathrm{BMI}$ is suggested to be the most important predictor of athlete success in endurance events. ${ }^{12-14}$ In addition, endurance performance may be affected by previous running experience. A study of female distance runners found that distance run per day was the sole factor predicting improved novice marathon performance, whereas performance in experienced runners was best predicted by BMI and workout pace. ${ }^{15}$

Cross-training, which is the incorporation of nonrunning exercise into the training program, is commonly believed to reduce injuries and improve running performance. However, there is little evidence in the peer-reviewed literature to support this common belief. Epidemiological studies have reported that higher weekly running distance is associated with increased hamstring injuries ${ }^{2,3,16}$ but reduced knee injuries. ${ }^{2}$ Smaller interventional studies have found no specific performance improvement due to cross-training. One study of 12 moderately trained (run 16-30 km/week, maximal oxygen consumption [ $\left.\mathrm{VO}_{2} \max \right] 55.3 \mathrm{~mL} / \mathrm{kg} / \mathrm{min}$ ) male runners compared a high-intensity cross-training program (cycling 2 days/week, running 2 days/week) with a similar intensity running only training program (4 days/week). At the end of 5 weeks, both groups had lowered their $5 \mathrm{~km}$ times and increased their aerobic capacity, but the differences between the two groups were not statistically significant. ${ }^{17}$ Another study involved 20 highly trained (minimum $32 \mathrm{~km} /$ week, $\mathrm{VO}_{2} \max 63 \mathrm{~mL} / \mathrm{kg} / \mathrm{min}$ ) male runners in a 6-week interventional study of either cycling plus running or running only. Both groups had similar improvements in $5 \mathrm{~km}$ running performance without significant changes in resting heart rate, resting blood pressure, serum cortisol, serum testosterone, or serum creatine kinase. ${ }^{18}$

Considering the popularity of marathons and the high number of nonelite runners, we conducted a preliminary study using a convenience sample of participants in the 2008 Twin Cities Marathon (TCM) to investigate the premarathon and postmarathon training programs of nonelite marathon runners. For most nonelite marathon finishers, qualifying for the Boston Marathon is considered a significant achievement.
Given that a "competitive training motive" has been cited as a risk factor for running injury, ${ }^{19}$ we specifically compared the anthropomorphic characteristics and training habits of Boston Marathon qualifiers with nonqualifiers in our sample. We hypothesized that qualifying runners would have higher running volumes, more running sessions per week, and a lower BMI compared with nonqualifying runners.

\section{Materials and methods Participant recruitment}

Study participants were solicited through Mile Marker, a monthly electronic newsletter by Twin Cities In Motion, the nonprofit corporation that organizes and directs the TCM, which was distributed to everyone who registered for the October 5, 2008 TCM. Information about the study and a link to the Web-based survey appeared in the November 2008 newsletter (November 21, 2008, all respondents by November 27 , 2008). A follow-up email with a link to the Web-based survey was sent to the original survey respondents 6 months after the marathon (April 18, 2009, all responded by April 27, 2009). The study protocol and survey instruments were approved by the University of Minnesota Institutional Review Board.

\section{Survey content}

Respondents to the initial survey provided their age, gender, height, weight, and marathon finishing time. A series of questions inquired about respondents' previous running experience: total number of marathons run (numerical free text), longest distance raced prior to the 2008 marathon $(5 \mathrm{~km}, 10 \mathrm{~km}$, half marathon, or self-report), and any prior participation in ultramarathons (yes/no) or triathlons (yes/no). Respondents were also asked to provide retrospective information about their premarathon training program (2 months premarathon, not including the tapering regimen immediately before the marathon) and information about their current exercise program (ie, exercise occurring at the time of survey completion). The following training program elements were assessed: number of running sessions per week (numerical free text), hours and distance per running session (numerical free text), and presence of injury that may have affected training (yes/no). To measure cross-training, the subjects were asked whether their training program included nonrunning activities (yes/no). If the answer was "yes", then cross-training options (swimming, biking, weight lifting, yoga, aerobics, in-line skating, roller skiing, power walking, Nordic walking or skiing, rowing, or other) were provided, and the subjects answered further questions about the training volume as numerical free text (sessions per week/hours per session/distance per session [as appropriate]). 
The 6-month postmarathon survey included a question that asked whether respondents' training habits had changed since the marathon (yes/no). The same items as in the initial survey were used to acquire information about the respondents' training program and injuries at this later time point.

\section{Data analysis}

Runners were classified as "qualifiers" if their TCM finish time was sufficient to qualify them for the Boston Marathon within their age category (Table 1). BMI was calculated by using the standard formula of weight $/$ height ${ }^{2}\left(\mathrm{~kg} / \mathrm{m}^{2}\right)$. Descriptive statistics were used to compare qualifiers and nonqualifiers. $T$-tests and Fisher's exact tests were used to compare continuous and categorical variables, respectively, between groups. McNemar's test was used to compare the changes in cross-training among the runners. $P$ values $<0.05$ were deemed to be statistically significant. SAS ${ }^{\circledR}$ Version 9.1.3 (SAS Institute Inc., Cary, NC, USA) was used for the analysis. Factors considered in the analysis were BMI, age, gender, first-time marathoner, participant in runs longer than marathon distance, triathlon participant, training was exclusively running, number of running sessions/week, longest run during week, and nonrunning training activity.

\section{Results}

The 2008 TCM had 8219 starters and 7970 finishers. A convenience sample of $50 \mathrm{TCM}$ participants completed the initial survey. Forty-nine of the respondents completed the marathon, and 13 (seven women, six men) were classified as "qualifiers" based on their running times. Forty-one of the initial 50 respondents $(82 \%)$ completed the 6-month follow-up survey.

Study participants' age, height, weight, BMI (1 month and 6 months postmarathon), marathon finish times, and prior running experiences are summarized in Table 2. There was no statistically significant difference between age or gender

Table I Qualifying times for the Boston Marathon

\begin{tabular}{lll}
\hline Age group (years) & \multicolumn{2}{l}{$\begin{array}{l}\text { Qualifying time by } \\
\text { gender (hr:min) }\end{array}$} \\
\cline { 2 - 3 } & Men & Women \\
\hline $18-34$ & $3: 10$ & $3: 40$ \\
$35-39$ & $3: 15$ & $3: 45$ \\
$40-44$ & $3: 20$ & $3: 50$ \\
$45-49$ & $3: 30$ & $4: 00$ \\
$50-54$ & $3: 35$ & $4: 05$ \\
$55-59$ & $3: 45$ & $4: 15$ \\
$60-64$ & $4: 00$ & $4: 30$ \\
\hline
\end{tabular}

in the qualifying versus nonqualifying groups. At 1 month postmarathon, qualifiers had a lower mean BMI than nonqualifiers (22.0 versus $23.9 \mathrm{~kg} / \mathrm{m}^{2}, P=0.0267$ ). However, at 6 months postmarathon, this group difference was no longer significant. At both survey time points, qualifier and nonqualifier runners had a mean BMI in the normal range. Only three runners (two qualifiers, one nonqualifier) reported completing a run longer than the marathon distance. There was no statistical difference in the number of qualifiers $(23 \%)$ versus nonqualifiers (14\%) who completed triathlons.

After completing the marathon, $82 \%$ of all runners reported changing their training program. One month after the marathon, one qualifier and three nonqualifiers were not training. By 6 months postmarathon, all participants had resumed some form of training.

Respondents' specific training habits at pre-, 1 month post-, and 6 months postmarathon, including amount of running and cross-training, are shown in Table 3. There was no statistical difference in the number of running sessions per week between qualifiers and nonqualifiers. The average number of running sessions per week decreased for both qualifiers and nonqualifiers in the month following the marathon, from 4.6/week prior to the marathon to 3.9/week 1 month after the marathon, and then increased again 6 months after the marathon to 4.4/week. However, these changes did not reach statistical significance at 1 month ( $t$-test; $P=0.6002$ ) or 6 months ( $t$-test; $P=0.2796$ ) after the marathon. Six months after the marathon, both qualifiers and nonqualifiers were running as many sessions per week as they had been before the marathon. Training session mileage ranged from 3 to 23 miles/session premarathon and decreased to 2-12 miles/session in the month following the marathon. Six months after the marathon, the range of miles run per session had increased to 3-30 miles/session.

Both qualifiers and nonqualifiers incorporated cross-training into their running programs, with no statistical difference between groups (Table 3). Just over half of all runners did some form of cross-training before the marathon, with the most common form of cross-training being biking $(81 \%)$. The percentage of runners doing some form of cross-training increased significantly from $54 \%$ before the marathon to $74 \% 1$ month after the marathon (McNemar's test; $P=0.0039$ ) and remained at $71 \%$ 6 months after the marathon (McNemar's test; $P=0.0325$ ). The most common types of cross-training for both groups were biking and weight lifting. The presence of cross-training did not have a significant association on injury rates $(14 \%$ cross-training vs $8 \%$ no cross-training: Fisher's exact test $P=1.0$ ) at 1 month or 6 months ( $21 \%$ vs $0 \%$ : Fisher's exact test $P=0.1557)$. 
Table 2 Demographic characteristics, anthropomorphic measures, and running experiences of survey respondents

\begin{tabular}{|c|c|c|c|}
\hline Variable & $\begin{array}{l}\text { Qualifying runners } \\
\mathrm{n}=13\end{array}$ & $\begin{array}{l}\text { Nonqualifying runners } \\
\mathrm{n}=\mathbf{3 7}\end{array}$ & $\begin{array}{l}\text { All surveyed runners } \\
\mathrm{n}=\mathbf{5 0}\end{array}$ \\
\hline Male, n (\%) & $6(46 \%)$ & $20(54 \%)$ & $26(52 \%)$ \\
\hline Female, n (\%) & $7(54 \%)$ & $16(43 \%)$ & $23(46 \%)$ \\
\hline Did not specify & & I & 1 \\
\hline Age in years, mean (SD) & $35.4(12.1)$ & $37.6(9.5)$ & $37.0(10.2)$ \\
\hline Range & $23-61$ & $23-58$ & $23-61$ \\
\hline Height in cm, mean (SD) & $17 \mid(9)$ & $173(9)$ & $172(9)$ \\
\hline Weight in kg, mean (SD) & $65(11)$ & $72(12)$ & $70(12)$ \\
\hline Body mass index in $\mathrm{kg} / \mathrm{m}^{2}(1 \text { month post })^{\mathrm{a}}$ & $22.0(2.0)$ & $23.9(2.6)$ & $23.4(2.6)$ \\
\hline Body mass index in $\mathrm{kg} / \mathrm{m}^{2}$ ( 6 months post) & $22.6(1.8)$ & $23.8(2.5)$ & $23.7(2.4)$ \\
\hline Marathon finish time in hr:min, mean & $3: 24$ & $4: 20$ & $4: 05$ \\
\hline Range $^{b}$ & $2: 56-3: 47$ & $3: 19-5: 58$ & $2: 56-5: 58$ \\
\hline First time marathoners, $\mathrm{n}(\%)$ & $2(15 \%)$ & $15(4 \mid \%)$ & $17(34 \%)$ \\
\hline Median number of prior marathons & 3 & I & 2 \\
\hline Range & $0-180$ & $0-27$ & $0-180$ \\
\hline $\begin{array}{l}\text { Participants who completed runs longer than the marathon } \\
\text { distance, } \mathrm{n}(\%)\end{array}$ & $2(15 \%)$ & I (3\%) & $3(6 \%)$ \\
\hline Participants who completed triathlons, n (\%) & $3(23 \%)$ & $5(14 \%)$ & $8(16 \%)$ \\
\hline
\end{tabular}

Notes: ${ }^{a}$-test $P=0.0267$ comparing qualifying with nonqualifying runners; ${ }^{b}$-test $P<0.0001$ comparing qualifying with nonqualifying runners.

One month after the marathon, $12 \%$ of the surveyed runners had sustained an injury that affected their training program ( $8 \%$ of qualifiers, $14 \%$ of nonqualifiers). Six months after the marathon, $15 \%$ of surveyed runners reported an injury (18\% qualifiers, $13 \%$ nonqualifiers). There was no statistical difference between qualifiers and nonqualifiers in injury rates at 1 month or 6 months after the marathon.

\section{Discussion}

In this study, nonelite runners who qualified for the Boston Marathon did not significantly differ in premarathon running frequency, run length, or cross-training volume compared with nonqualifying runners. Qualifying runners had a lower BMI than nonqualifying runners at 1 month postmarathon, but did not otherwise differ in terms of injury rates or training program either pre- or postmarathon. Cross-training, particularly cycling and weight lifting, was a significant component of their marathon training program, with cross-training rates increasing significantly postmarathon. However, the presence of cross-training did not appear to modify self-reported injury rates.

For many marathon finishers, qualifying for the Boston Marathon is a personal goal and, if met, a significant achievement. In 2009, the median time (all ages inclusive) for US marathon finishers was 4:13:36 for men and 4:41:26 for women. ${ }^{1}$ Only $26 \%$ of participants in our study would be considered a qualifying runner. Although this criterion may not necessarily be considered competitive among professional runners, it is a potentially laudable goal for many nonelite runners.
The question then arises whether differences in a runner's training program or other factors can facilitate achieving this goal. At a group level, no clear differences were observed in the training programs of qualifying versus nonqualifying runners in terms of the number of training sessions per week, range of miles run per session, or incorporation of cross-training in the exercise regimen. However, from this data, we cannot determine whether changes at an individual level may facilitate a change in qualification status. These results suggest that longitudinal studies would be important for evaluating training effects on performance in nonelite runners, particularly focusing on changes in workout intensity and cross-training volume over time.

At 1 month postmarathon, qualifying runners did have a slightly lower mean BMI than nonqualifying runners. Because we distributed the survey postmarathon, a premarathon BMI was unavailable. However, the 1 month postmarathon BMI provided a surrogate measure for the premarathon BMI. Coupled with the finding that the measured training variables were not significantly different for qualifiers and nonqualifiers, this result provides preliminary evidence that nontraining factors related to BMI may affect running performance. This is similar to other studies that have shown anthropomorphic variables such as BMI to have an important association with endurance performance. ${ }^{14,15} \mathrm{At}$ 6 months postmarathon, there was a lack of statistical difference in BMI between qualifying and nonqualifying runners. Although we did not see any significant differences between groups in training frequency or cross-training after the marathon, changes in diet or exercise intensity (not measured) 


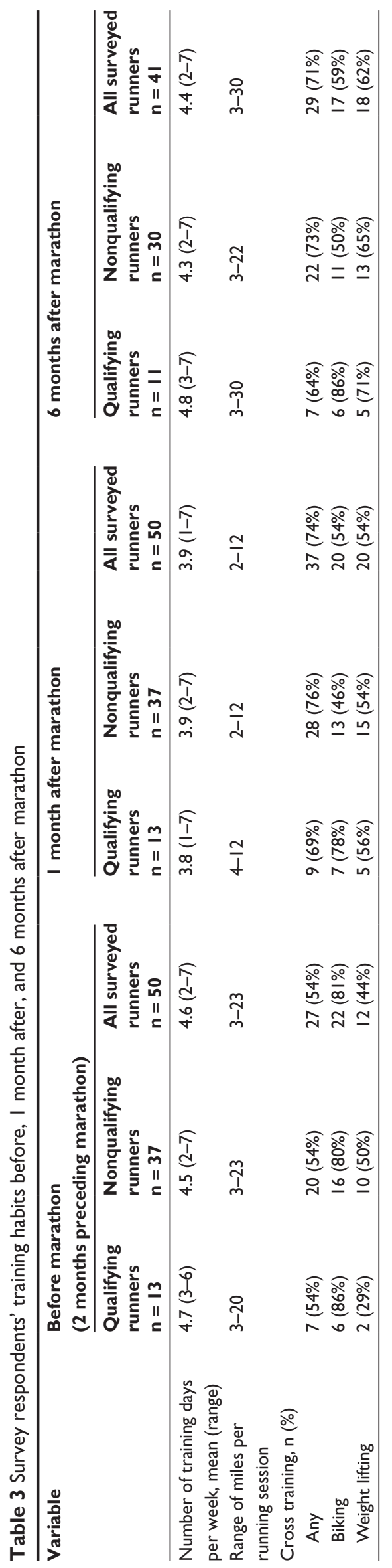

might be potential factors. Whether the lower BMI 1 month postmarathon is indicative of a higher training intensity remains to be determined. Likewise, whether the change in BMI between the 1 month and 6 month postmarathon surveys, although remaining in the normal range, might affect running performance remains unknown. Given these preliminary results, further validation using a prospective cohort study would be recommended.

There is much interest in the role of cross-training as a means to reduce injury. In this study, qualifying and nonqualifying runners did not have significant differences in the incorporation of cross-training in their exercise regimen or in their injury rates. The most common types of cross-training for both groups were biking and weight lifting. There was a significant increase in the number of runners performing crosstraining 1 month and 6 months after the marathon. Whether or not this type of cross-training improves running performance is controversial, as several interventional studies show no improvement in running performance with cross-training. ${ }^{17,18}$ Although there was no statistical difference in the injury rates related to cross-training, for the practitioner, the presence of cross-training should be kept in mind when addressing musculoskeletal injuries observed in a marathon runner.

There are several study weaknesses. Given the intent of studying nonelite marathon finishers, the survey was limited by participants' self report of their training program and injury rates. The response rate $(0.6 \%)$ was low relative to the total number of marathon finishers, and selection bias may be present, as those participants who chose to complete the survey may have different training programs than those who did not complete the survey. However, the data appear still to be applicable as the median age and median times in the study participants are comparable with published data of the average US marathon finisher. ${ }^{1}$ Another weakness was that the survey measured running intensity as number of sessions/week and miles/session rather than the total training volume in miles/week. Because many marathon runners include one long run and several shorter runs in a week, the survey questions may not reflect the average weekly running volume. Despite these weaknesses, this survey demonstrates the feasibility of a Web-based survey to describe training habits and provides novel and meaningful descriptive data about training habits of nonelite marathon runners that physicians/trainers might encounter in practice.

\section{Conclusion}

In summary, BMI was significantly lower in qualifying than in nonqualifying runners at 1 month postmarathon but not 
at 6 months postmarathon. We did not find any significant differences in training volume (running frequency, run length, or cross-training volume) between qualifying and nonqualifying runners. Cross-training was common in both qualifiers and nonqualifiers, with a significant increase in the amount of cross-training after the marathon. Given the limitations of the study design, we could not definitively conclude whether or not changes in the training program (duration, intensity, cross-training) would facilitate the transition from nonqualifying to qualifying status. Further prospective cohort studies examining the training program and BMI, perhaps using Web-based surveys for convenience, are recommended.

\section{Acknowledgments}

We would like to thank Anne-Marie Weber for her editorial comments, and Lee Snyder for the survey design and data collection. Funding was provided by National Institutes of Health 5K12RR023247-02 (LSC). We would also like to thank Virginia Achman and the staff of Twin Cities in Motion for their assistance with the survey distribution and recruitment.

\section{Disclosure}

The authors have no conflicts of interest to declare.

\section{References}

1. Running USA Inc. Running USA Annual Marathon Report. http://www. runningusa.org/node/57770\#57771. Accessed December 1, 2010.

2. Satterthwaite P, Norton R, Larmer P, Robinson E. Risk factors for injuries and other health problems sustained in a marathon. Br J Sports Med. 1999;33(1):22-26.
3. Marti B, Vader JP, Minder CE, Abelin T. On the epidemiology of running injuries. Am J Sports Med. 1988;16(3):285-294.

4. Arrese AL, Ostariz ES. Skinfold thicknesses associated with distance running performance in highly trained runners. $J$ Sports Sci. 2006;24(1):69-76.

5. Larsen HB. Kenyan dominance in distance running. Comp Biochem Physiol Mol Integr Physiol. 2003;136(1):161-170.

6. Lucia A, Esteve-Lanao J, Olivan J, et al. Physiological characteristics of the best Eritrean runners - exceptional running economy. Appl Physiol Nutr Metab. 2006;31(5):530-540.

7. Billat VL, Demarle A, Slawinski J, et al. Physical and training characteristics of top-class marathon runners. Med Sci Sports Exerc. 2001;33(12):2089-2097.

8. Knechtle B, Knechtle P, Rosemann T. Skin-fold thickness and training volume in ultra-triathletes. Int J Sports Med. 2009;30(5):343-347.

9. Knechtle B, Kohler G. Running performance, not anthropometric factors, is associated with race success in a Triple Iron Triathlon. Br J Sports Med. 2009;43(6):437-441.

10. Christensen CL, Ruhling RO. Physical characteristics of novice and experienced women marathon runners. $\mathrm{Br} J$ Sports Med. 1983;17(3):166-171.

11. Leake CN, Carter JEL. Comparison of body composition and somatotype of trained female triathletes. J Sports Sci. 1991;9(2):125-135.

12. Sleivert GG, Rowlands DS. Physical and physiological factors associated with success in the triathlon. Sports Med. 1996;22(1):8-18.

13. Bale P, Bradbury D, Colley E. Anthropometric and training variables related to $10 \mathrm{~km}$ running performance. Br J Sports Med. 1986;20(4):170-173.

14. Campbell MJ. Predicting running speed from a simple questionnaire. Br J Sports Med. 1985;19(3):142-144.

15. Hagan RD, Upton SJ, Duncan JJ, Gettman LR. Marathon performance in relation to maximal aerobic power and training indices in female distance runners. Br J Sports Med. 1987;21(1):3-7.

16. Walter SD, Hart LE, McIntosh JM, Sutton JR. The Ontario cohort study of running-related injuries. Arch Intern Med. 1989;149(11):2561-2564.

17. Mutton DL, Loy SF, Rogers DM, et al. Effect of run vs combined-cycle run training on Vo(2max) and running performance. Med Sci Sports Exerc. 1993;25(12):1393-1397.

18. Flynn MG, Carroll KK, Hall HL, et al. Cross training: indices of training stress and performance. Med Sci Sports Exerc. 1998;30(2):294-300.

19. Fredericson M, Misra AK. Epidemiology and aetiology of marathon running injuries. Sports Med. 2007;37(4-5):437-439.
Open Access Journal of Sports Medicine

\section{Publish your work in this journal}

Open Access Journal of Sports Medicine is an international, peer-reviewed, open access journal publishing original research, reports, reviews and commentaries on all areas of sports medicine. The manuscript management system is completely online and includes a very quick and fair peer-review system.

\section{Dovepress}

Visit http://www.dovepress.com/testimonials.php to read real quotes from published authors. 